\title{
Effect of the epiphytic bacterium Bacillus sp. WPySW2 on the metabolism of Pyropia haitanensis
}

\author{
Yuqin Xiong ${ }^{1} \cdot$ Rui Yang ${ }^{1,2} \cdot$ Xiaoxiao Sun ${ }^{1} \cdot$ Huatian Yang ${ }^{1,2} \cdot$ Haimin Chen ${ }^{1,2}$
}

Received: 25 February 2017 /Revised and accepted: 14 September 2017/Published online: 2 December 2017

(C) The Author(s) 2017. This article is an open access publication

\begin{abstract}
A variety of different symbiotic microbial communities are harbored on the surface of seaweeds, the interactions of which depend upon nutritional exchanges between the microbes and the hosts. Metabolomic profiling is able to provide a comprehensive and unbiased snapshot of the metabolites associated with seaweed-microbe interactions. In this study, the relationships between phycosphere bacteria and the red alga Pyropia haitanensis were investigated on a metabolomic basis using gas chromatography-mass spectrometry, and the pathways of the interactions between the seaweed and its associated phycospheric microbes were revealed. Bacillus sp. WPySW2, one bacterial species isolated from the phycosphere of Pyropia species, had a significant influence on the metabolomic profile of the algae. Some of the intracellular metabolites such as phenylalanine, leucine, isoleucine, valine, proline, tyrosine, threonine, octadecanoic acid, hexadecanoic acid, and citric acid were downregulated in the thalli of P. haitanensis when it was co-cultured with Bacillus sp. WPySW2, while several special metabolites including melibiose, serine, glycerol-3-phosphate, galactosylglycerol, and alanine were upregulated. The results demonstrated that
\end{abstract}

Electronic supplementary material The online version of this article (https://doi.org/10.1007/s10811-017-1279-z) contains supplementary material, which is available to authorized users.

Rui Yang

yangrui@nbu.edu.cn

1 Key Laboratory of Marine Biotechnology of Zhejiang Province, Ningbo University, No. 818 Fenghua Road, Post Box 71, Ningbo, Zhejiang 315211, China

2 Li Dak Sum Yip Yio Chin Kenneth Li Marine Biopharmaceutical Research Center, Ningbo University, Ningbo, Zhejiang 315211, China
$P$. haitanensis grew better when it was co-cultured with Bacillus sp. WPySW2 at $20{ }^{\circ} \mathrm{C}$. In conclusion, several main intracellular metabolites were downregulated and upregulated, which might have facilitated bacterial colonization.

Keywords Bacillus sp. P Pyropia haitanensis · Phycosphere · Co-culture $\cdot$ Metabolomics

\section{Introduction}

In the marine environment, the surfaces of seaweeds harbor a variety of different symbiotic microbial communities that influence the development and physiological status of their host (Wahl et al. 2012). The seaweeds provide photosynthate to their microbial neighbors in return for a habitat that protects the host from desiccation or light, gases, and/or nutrient stress and modulates the host's interaction with additional foulers, consumers, or pathogens (Hawksworth 1988; Wahl et al. 2012). Other symbiotic interactions exist. For example, the biomass of microalga Dunaliella sp. accumulated with the presence of two bacteria strains affiliated to Alteromonas sp. and Muricauda sp., and the bacteria helped the algae accumulate nitrogen (Chevanton et al. 2013). These symbiotic relationships suggest that seaweeds and their epiphytic bacteria interact in a type of substance metabolism, complementing the living environment to form a specific environment (Egan et al. 2013), defined as a "phycosphere" (Bell and Mitchell 1972). Some symbiotic bacteria isolated from seaweeds could produce secondary materials that exhibited antibacterial activity (Vijayalakshmi 2015; Albakosh et al. 2016).

In the rhizosphere, the gram-positive bacterium Bacillus species are important symbionts of the terrestrial plant roots (Vlamakis et al. 2013). Bacillus species also commonly inhabit the marine environments (Olmos-Soto 2014), and have been found to be dominant in the phycosphere of Pyropia and 
Ulva species (Yang et al. 2008; Shen et al. 2013). The effects of troponoid compounds derived from the genus Phaeobacter on an algal-bacterial symbiosis were also reported (Seyedsayamdost et al. 2011). Seaweeds themselves also secrete surface-associated secondary metabolites, enabling chemical defense against bacterial colonization. It was reported that macroalgae regulate the behavior of algal surface epiphytic bacteria directly through bromine and chlorine, 1,1,3,3tetrabromo-2-heptanone, and furanones, sesquiterpenes (Vairappan et al. 2008; Nylund et al. 2010; Persson et al. 2011; Fernandes et al. 2012; Carvalho et al. 2017), oxidase (Weinberger et al. 2011), proline (Lachnit et al. 2010; Saha et al. 2014), free fatty acid derivatives, (Lion et al. 2006) and bromophycolides (Lane et al. 2009). For microbial-microbial interactions, probiotics or symbiotic bacteria act as the trigger of chemical defenses of the other microbial communities and alter the microbial flora in the phycosphere (Wahl et al. 2012). Enzymes such as $N$-acyl homoserine lactone (AHL)-acylase and AHL-lactonase are produced by Bacillus spp., which might act as pathogen community inhibitors (Cao et al. 2012).

Pyropia haitanensis occurs locally in the Zhejiang and Fujian provinces in China which is primarily cultivated in these areas and is of great commercial importance (Chen et al. 2011). Many pathogenic microbes that cause serious disease in Pyropia species have been reported, including Cobetia marina, Pseudoalteromonas citrea, Pythium porphyrae, and so on (Takahashi et al. 1977; Yan et al. 2002, 2008; Huang and Yan 2010). However, the pathogenic bacteria might not be the only cause of algal disease. Shen et al. (2013) reported that many bacterial strains isolated from the healthy thalli of $P$. haitanensis were highly similar to these virulent algal pathogens. The species and biomass of bacteria in the Pyropia phycosphere were found to vary with the algal species and culture conditions, the physiological status (health and disease), and algal development stages (Yang et al. 2008). The common bacteria species found in phycosphere include Pseudoalteromonas, Psychrobacteria, and Bacillus (Yan et al. 2002; Wang et al. 2011). Fang et al. (2009) reported that 3 PKS I positive Bacillus strains (WPhG3, WPySW1, and WPySW2) isolated from the phycosphere of cultivated $P$. haitanensis had powerful antibacterial activities, similar to many Bacillus subtilis strains reported in some terrestrial plants (Chung et al. 2015). Bacillus species were also able to increase the content of chlorophyll in rice, increase the fresh weight and dry weight of the plant, enhance the activities of protection enzymes, advance the resistance to adversity by improving adjustability, and promote the growth of seedlings (Cai et al. 2005; Yang et al. 2010). Song et al. (2014) reported that the inhibition of calcification reaction of Pleurochrysis carterae by the phycospheric Psedudoalteromonas sp. NPyS3 was significantly greater than that of lower $\mathrm{pH}$.

Metabolomic profiling provides an applicable and unbiased snapshot of metabolites belonging to predefined groups, including organic acids, fatty acids, sugars, and amino acids (Agarrwal et al. 2014). Analytical techniques such as gas chromatography-mass spectrometry (GC-MS) have been successfully applied to investigate and profile the metabolic variation associated with different conditions as for example, the responses of cassava (Manihot esculenta) roots during postharvest physiological deterioration (Uarrota et al. 2014). Therefore, metabolomic analysis has been shown to be a powerful tool for gaining new insights and a better understanding of the metabolic responses to biotic factors. In this study, we investigated the relationship between phycosphere bacteria and $P$. haitanensis by detecting the metabolite basis with GC-MS techniques and revealing the pathways of the interactions between the seaweed and associated phycosphere microbes.

\section{Materials and methods}

Bacillus sp. WPySW2 was isolated from the phycosphere of rotten Pyropia species cultivated in Wenzhou area and preserved in the Key Laboratory of Marine Biotechnology of Zhejiang Province, Ningbo University, China. The NCBI code number of 16S sRNA sequence is EU863221. The bacteria were incubated in $250-\mathrm{mL}$ flasks containing $100 \mathrm{~mL}$ 2216E medium (Patrick 1978) and cultured at $37{ }^{\circ} \mathrm{C}$ and $140 \mathrm{rpm}$ for $12 \mathrm{~h}$. The cells were diluted to the concentration of $10^{8}$ cells $\mathrm{mL}^{-1}$, centrifuged for $1 \mathrm{~min}$ at $5000 \times \mathrm{g}$ to remove the $2216 \mathrm{E}$ medium, and suspended in a small amount of sterile cultured medium $\left(v / v\right.$ : mixed solution $\mathrm{KNO}_{3} 100 \mathrm{~g} \mathrm{~L}^{-1}$ and $\mathrm{KH}_{2} \mathrm{PO}_{4} 10 \mathrm{~g} \mathrm{~L}^{-1}$ : sterile seawater = 1:1000; Zhou et al. 2012).

Pyropia haitanensis thalli were collected in October 2014 from the culture area of the Dongtou coast, Zhejiang Province, China. After being naturally dried, the thalli were sealed and stored at $-20^{\circ} \mathrm{C}$. The samples were recovered with seawater at $20^{\circ} \mathrm{C}$ for $24 \mathrm{~h}$ and examined under a microscope. Healthy thalli were cleaned three times with a soft brush in sterile seawater and soaked in $0.7 \% \mathrm{KI}(w / v)$ for $10 \mathrm{~min}$. The samples were then cleaned three times again using sterile seawater for further use. The cleaned thalli were immersed in a combination of the antibiotics - ampicillin (final concentration $300 \mu \mathrm{g} \mathrm{mL}^{-1}$ ), kanamycin (final concentration $100 \mu \mathrm{g} \mathrm{mL}^{-1}$ ), and gentamicin (final concentration $100 \mu \mathrm{g} \mathrm{mL}^{-1}$ )-for $18 \mathrm{~h}$ and cleaned with sterile seawater (Zhou et al. 2012).

\section{Determination of $P$. haitanensis biomass}

The cleaned antibiotic treated algae pieces (ca. 0.2 g) were treated with suspended bacteria $\left(3 \times 10^{8}\right.$ cells $\left.\mathrm{mL}^{-1}\right)$ and incubated in $300-\mathrm{mL}$ sterile flasks containing sterile cultured medium. The flasks were left standing at $20^{\circ} \mathrm{C}$ for 9 days (light intensity 50-70 $\mu \mathrm{mol}$ photons $\mathrm{m}^{-2} \mathrm{~s}^{-1}, \mathrm{~L}: \mathrm{D}=12 \mathrm{~h}: 12 \mathrm{~h}$ ). 
We measured the fresh weight of the algae every 3 days and calculated the relative growth rate of the algae using the formula: relative growth rate $(\mathrm{RGR})(\% /$ day $)=\left[\mathrm{Ln}\left(\mathrm{M}_{\mathrm{t}} / \mathrm{M}_{\mathrm{o}}\right) / \mathrm{t}\right] \times 100$ (Kain 1987).

\section{P. haitanensis-Bacillus sp. WPySW2 co-cultures}

The cleaned thalli $(0.2 \mathrm{~g})$ were selected randomly and co-cultured with suspended bacteria $\left(3 \times 10^{8}\right.$ cells $\mathrm{mL}^{-1}$ ) and incubated in $300 \mathrm{~mL}$ sterile nutrient enriched seawater. The co-cultured systems (B-Ph) were incubated at $20{ }^{\circ} \mathrm{C}$ under a $12 \mathrm{~h} / 12 \mathrm{~h}$ light/dark regime with $50-70 \mu \mathrm{mol}$ photons $\mathrm{m}^{-2} \mathrm{~s}^{-1}$ illumination. The control groups (pure culture of $P$. haitanensis, $\mathrm{Ph}-$ $\mathrm{C}$ group) were inoculated in the flasks under identical sterile cultured medium and concentration conditions as above.

The experiments were repeated three times and the samples were collected for further analysis. The progress of co-culture was recorded by microscopy. At the end of culture, the thalli were collected and immersed in $0.1 \%(w / v)$ ampicillin for $10 \mathrm{~min}$ and thereafter cleaned three to five times with sterile seawater to remove the epiphytic bacteria. The surface water was absorbed, and the samples were frozen with liquid nitrogen and transported to the $-80{ }^{\circ} \mathrm{C}$ freezer as quickly as possible.

\section{Metabolite extraction and metabolite profiling analysis}

The metabolites of the thalli (cultured for 3 days) were extracted according to Lisec et al. (2006), with some modifications. Eight repeat samples (100 mg fresh weight per sample) of both the control and the co-culture systems were collected randomly and stored at $-80{ }^{\circ} \mathrm{C}$ for metabolite analysis. The samples were ground in liquid nitrogen and transferred into 2 -mL centrifuge tubes. In total, $1200 \mu \mathrm{L}$ of $100 \%$ methanol (pre-cooled at $-20^{\circ} \mathrm{C}$ ) was added and vortexed for $10 \mathrm{~s}$; then $60 \mu \mathrm{L}$ of ribitol $\left(0.2 \mathrm{mg} \mathrm{mL}^{-1}\right.$ stock in $\left.\mathrm{dH}_{2} \mathrm{O}\right)$ was added as an internal quantitative standard and vortexed for $10 \mathrm{~s}$. The tubes were placed into an ultrasonic processor at $70{ }^{\circ} \mathrm{C}$ for $30 \mathrm{~min}$ and then centrifuged for $10 \mathrm{~min}$ at $11000 \times \mathrm{g}$. One milliliter supernatant was transferred into $10-\mathrm{mL}$ glass centrifuge tubes. After adding $750 \mu \mathrm{L}$ chloroform (pre-cooled at $-20^{\circ} \mathrm{C}$ ) and $1500 \mu \mathrm{L}$ deionized water $\left(\mathrm{dH}_{2} \mathrm{O} ; 4{ }^{\circ} \mathrm{C}\right)$, the tubes were vortexed for $30 \mathrm{~s}$, then centrifuged for $15 \mathrm{~min}$ at $3000 \times \mathrm{g}$. Then, $1000 \mu \mathrm{L}$ supernatant was transferred into a new Eppendorf tube. The samples were blow-dried with a moderate nitrogen stream. Next, $50 \mathrm{~L}$ of $15 \mathrm{mg} \mathrm{mL}^{-1}$ methoxyamine pyridine solution was then added, and the mixture was vortexed for $30 \mathrm{~s}$ and reacted for $90 \mathrm{~min}$ at room temperature. Finally, $50 \mu \mathrm{L}$ BSTFA reagent (containing 1\% TMCS) was added to the mixture and reacted for $60 \mathrm{~min}$ at $70{ }^{\circ} \mathrm{C}$. Following the above reactions, the samples were determined for metabolite contents using an Agilent 7890A GC system coupled to an Agilent 5975C inert XL EI/CI mass spectrometric detector (MSD) system (Agilent Technologies, USA). Furthermore, mixed n-alkane standard solutions $\mathrm{C}_{8}-\mathrm{C}_{20}$ and $\mathrm{C}_{21}-\mathrm{C}_{40}$ (Sigma Aldrich) were used for the determination of retention indices (RI).

\section{GC-MS analysis}

Gas chromatography was performed on an HP-5MS capillary column (5\% phenyl-95\% methylpolysiloxane, $30 \mathrm{~m} \times 250 \mu \mathrm{m}$ i.d., 0.25- $\mu \mathrm{m}$ film thickness; Agilent J \& W Scientific, USA) to separate the derivatives at a constant flow of $1 \mathrm{~mL} \mathrm{~min}^{-1}$ helium. Then, $1 \mu \mathrm{L}$ of sample was injected in split mode in a 20:1 split ratio by the auto-sampler. The injection temperature was $280^{\circ} \mathrm{C}$, the interface was set to $150^{\circ} \mathrm{C}$, and the ion source was adjusted to $230{ }^{\circ} \mathrm{C}$. The temperature-rise program was initial temperature of $80{ }^{\circ} \mathrm{C}$ held for $5 \mathrm{~min}$, thereafter increased at a rate of $20^{\circ} \mathrm{C} \mathrm{min}^{-1}$ up to $300^{\circ} \mathrm{C}$, and maintained at $300^{\circ} \mathrm{C}$ for $6 \mathrm{~min}$. Mass spectrometry was determined using the full-scan method in the range of 35 to $500 \mathrm{~m} / \mathrm{z}$.

For the quality control (QC) samples (Sangster et al. 2006), an aliquot (about $40 \mathrm{uL}$ ) of all prepared sample extracts was mixed. These QC samples were used to monitor deviations of the analytical results from these pooled mixtures and compare them to the errors caused by the analytical instrument itself. The QC pool was subsequently divided over 10 vials and analyzed regularly throughout the entire analysis batch. Additionally, empty vials (blank injections) were included into the measurement sequence to test for laboratory contamination.

\section{Data processing}

Raw GC-MS data were converted into CDF format (NetCDF) files by Agilent GC/MS 5975 Data Analysis software and subsequently processed using XCMS (www.bioconductor. org), implementing the default settings with the following modifications: $x \mathrm{cmsSet}$ (fwhm $=3$, snthresh $=3$, zzdiff $=0$. 5 , step $=0.1$, steps $=2, \max =300)$ and group $(b w=2$, minfrac $=0.3, \max =300$ ). The signal integration area of each metabolite was normalized to the internal standard (ribitol) for each sample. Identification of metabolites using the Automatic Mass Spectral Deconvolution and Identification System (AMIDS) was searched against commercial available databases such as the National Institute of Standards and Technology (NIST) and Wiley libraries. Metabolites were confirmed by comparison of mass spectra and retention indices to the spectra library using a cut-off value of $70 \%$ (Dawud et al. 2012).

\section{Multivariate statistical analysis}

For multivariate statistical analysis, the XCMS output was further processed using Microsoft Excel (Microsoft, USA). 
Finally, the normalized data were imported into Simca-P software (version 11.0, http://www.umetrics. com/simca) for multivariate statistical analyses, including principal component analysis (PCA) and partial least squaresdiscriminant analysis (PLS-DA). All data were meancentered and unit variance (UV)-scaled before PCA and PLS-DA were applied in order to guard against overfitting. In this study, a default sevenfold (Leave-1/7th samples-Out) cross validation procedure, as well as 100 random permutation testing, was performed to guard against overfitting of supervised PLS-DA models. $R^{2} X$ and $R^{2} Y$ represent the fraction of the variance of the $x$ and $y$ variables explained by the model, while $Q^{2} Y$ suggests the predictive performance of the model. The cumulative values of $R^{2} X, R^{2} Y$, and $Q^{2} Y$ vary from 0 to 1 .

These discriminating metabolites were obtained by using a statistically significant threshold of variable influence on projection (VIP > 1.0) values obtained from the PLS-DA model and were further validated by Student's $t$ test. The metabolites with VIP values greater than 1.0 and $p$ values less than 0.05 (threshold) were selected as discriminating metabolites between two classes of samples.

\section{Statistical analysis}

Hierarchical cluster analysis (HCA) was performed and visualized using the heatmap package in R (www.r-project.org). Pearson's product-moment correlation (Pearson's $r$ ) was performed to calculate the correlation. Corresponding $p$ values and false discovery rate (FDR) (Benjamini and Yekutieli 2001) of each correlation were also calculated using the Cor. test function in R. Identified metabolites were mapped onto general biochemical pathways according to annotation in KEGG (Kyoto Encyclopedia of Genes and Genomes). Metabolic network maps were constructed by incorporating the identified and annotated metabolites using Cytoscape 3.2. 0 software (http://www.cytoscape.org/).

\section{Results}

\section{WPySW2 colonization on the surface of the seaweed}

WPySW2 colonized on the surface of the algal thalli when it was co-cultured with $P$. haitanensis (Fig. 1), while the surface

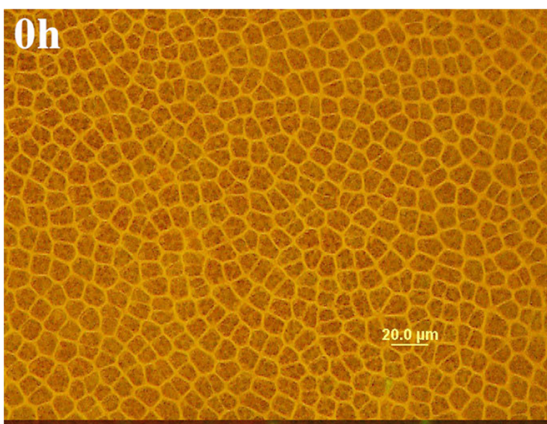

\section{$12 \mathrm{~h}$}
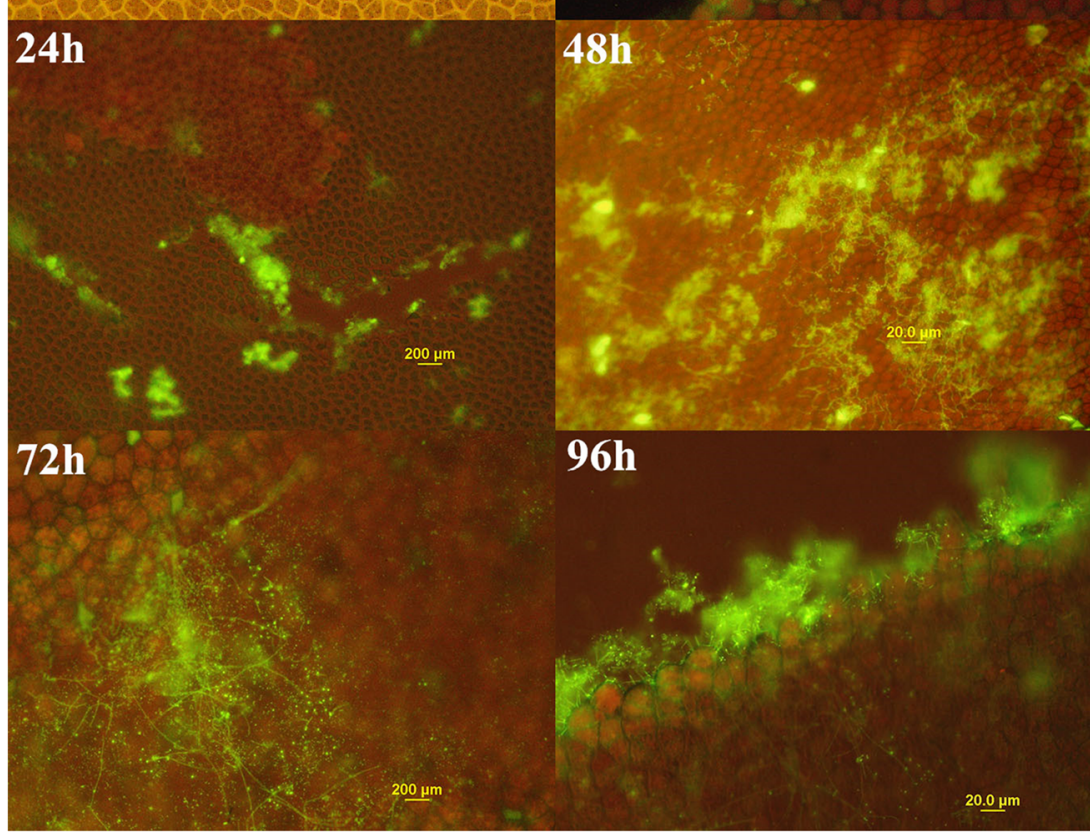

Fig. 1 Bacterial colonization on the surface of $P$. haitanensis thalli in the co-culture systems 
of the control group remained clean for a long time. After being cultured for $12 \mathrm{~h}$, the bacteria began to contact to the surface of thalli. The small pieces of green fluorescence were blocked, and the bacteria assembled continually as time went by. It was observed that bacteria preferred to accumulate at the edge of the leaves of the wound, which might provide more nutrient for the bacterial growth.

\section{Relative growth rate of $P$. haitanensis}

The two-way ANOVA results revealed that the relative growth rate (RGR) of $P$. haitanensis thalli at $20{ }^{\circ} \mathrm{C}$ was significantly promoted by Bacillus sp. WPySW2 $(p<0.01)$ and the culture time $(p<0.05$; Fig. 2$)$, and the bacteria had greater effects. These Gram-positive bacteria exhibited similar features as plant growth hormones. An increasing growth trend was observed in the P. haitanensis thalli from day 3 to day 9 . The highest RGR was obtained in the co-cultured system $(\mathrm{B}-\mathrm{Ph})$ at day 9 , which was $5.99 \%$ day $^{-1}$, while the RGR of the control (Ph-C) group was only $4.15 \%$ day $^{-1}$. The RGR at day 3 in the B-Ph group was 2.06 times that in the $\mathrm{Ph}-\mathrm{C}$ group, while the ratio of RGR between the $\mathrm{B}-\mathrm{Ph}$ and $\mathrm{Ph}-\mathrm{C}$ groups declined to 1.57 and 1.44 times at day 6 and day 9 .

\section{Cluster analysis of metabolite profiles}

Cluster analysis is a multivariate statistical analysis method to classify samples or indicators. Cluster analysis originated in taxonomy (Zhang et al. 2008; Real et al. 2012; Farag et al. 2012;), and a large number of samples have been classified reasonably using their respective features. Hierarchical

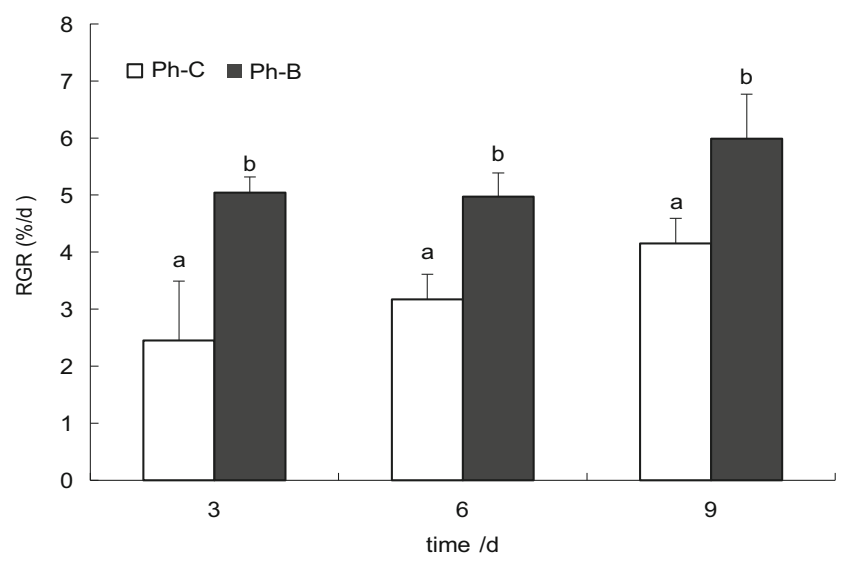

Fig. 2 The influence of bacteria on the growth of Pyropia haitanensis. Relative growth rates in $\%$ day $^{-1}$ of $P$. haitanensis algae after 9 days of incubation in the sterile seawater under different conditions (see the "Materials and methods" section). Mean values \pm SD $(n=3)$ and the figure indicate significantly increased of the growth rates (two-way ANOVA) driven by bacteria and culture time $(p<0.05)$ (B-Ph: $P$. haitanensis thalli co-cultured with Bacillus sp. WPySW2, Ph-C: P. haitanensis cultured without bacteria) clustering analysis (HCA) was performed to classify the control (Ph-C) and co-culture (B-Ph) metabolites. These 72 metabolites covered different primary metabolism pathways and some of the secondary metabolism pathways and were classified into several major metabolite groups (Fig. 3). As shown in Table 1, 15 metabolites varied significantly between the Ph$\mathrm{C}$ and the B-Ph samples. Five metabolites (including serine, melibiose, alanine, galactosylglycerol, and glycerol-3-phosphate) exhibited higher levels in co-culture B-Ph samples, while 10 (including octadecanoic acid, hexadecanoic acid, leucine, valine, citric acid, proline, tyrosine, threonine, phenylalanine, and isoleucine) exhibited lower levels in $\mathrm{B}-\mathrm{Ph}$ groups.

\section{Metabolite-metabolite correlation analysis}

Pearson's pairwise correlation coefficients were calculated for each pair of identified metabolites and visualized on a heatmap. Metabolite-metabolite correlations between the tissue of the $\mathrm{Ph}-\mathrm{C}$ and $\mathrm{B}-\mathrm{Ph}$ samples showed unique profiles. In the control, a total of 2556 correlations were analyzed, and out of these metabolite correlations, 506 resulted in significant correlation coefficients $(p<0.05)$. Out of these significant correlations, 330 were positive and 176 were negative (Fig. 4a). In the co-culture samples, 2556 correlations were also analyzed, and out of these metabolite correlations, 255 resulted in significant correlation coefficients $(p<0.05)$. Out of these 255 significant correlations, 192 were positive and 63 were negative (Fig. 4b).

\section{Correlation-based network analysis to identify $P$. haitanensis-induced metabolic perturbation}

Further screening of the correlations was performed, and 2 were determined to be significant with an $r^{2} \geq 0.49$ and a false discovery rate (FDR) $\leq 0.05$ in the co-culture samples, among which 2 constituted positive correlations and 0 constituted negative correlations (Fig. 5). In the controls, there were only 41 significant correlations with an $r^{2} \geq 0.49$ and FDR $\leq 0.05$ identified. Among them, 29 were positive correlations, while 12 were negative correlations. Organic acids and amino acids also played important roles in the metabolite correlations.

\section{KEGG pathway visualization}

To visualize the metabolic pathways of the identified metabolites, a comprehensive metabolic map was constructed from the identified 72 metabolites with annotated pathway information in KEGG. These metabolites covered pathways or metabolisms that include aminoacyl-tRNA biosynthesis, citric acid cycle (TCA cycle), amino acid metabolism, sugar 


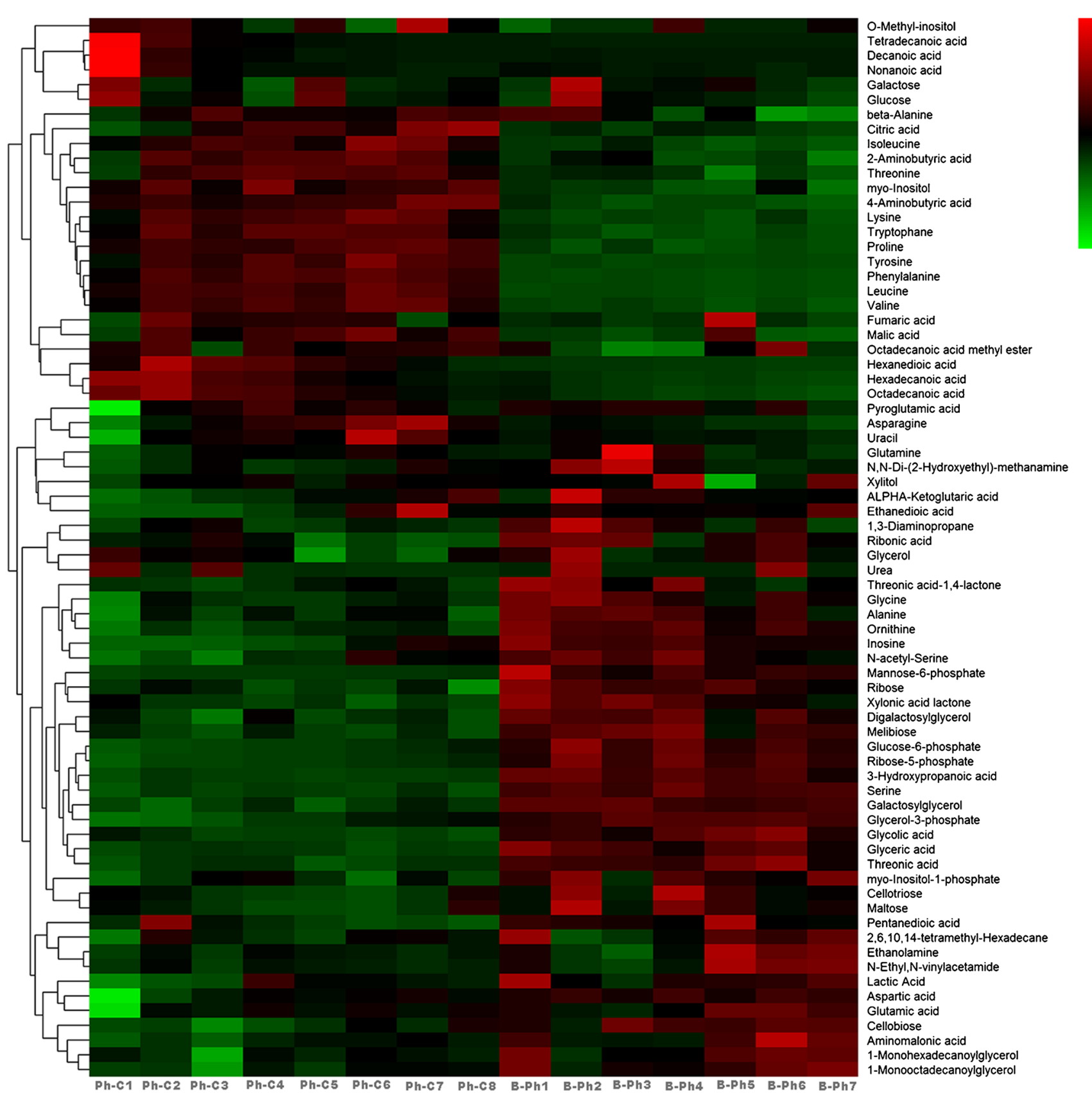

Fig. 3 Heatmap of cellular metabolites profile from P. haitanensis in control ( $\mathrm{Ph}-\mathrm{C})$ and co-culture samples (B-Ph)

metabolism, and biosynthesis of secondary metabolites. We used "biosynthesis of plant secondary metabolites" as an example in Supplementary Fig. 6.

\section{Discussion}

Seaweeds act as primary producers in marine ecosystems and engage in symbiosis with other organisms such as bacteria and fungi (Cooper and Smith 2015). The colonization of bacteria on the algal surface was displayed in the results, which indicate the physical basis for the interaction between algae and bacteria. Seaweed-bacteria interactions are mainly categorized into nutrient exchanges (Kouzuma and Watanabe 2015). A typical example of such an interaction is the supply of vitamin $\mathrm{B}_{12}$ by bacterial species to their seaweed partners in exchange for fixed carbon (Hodson et al. 2005; Helliwell et al. 2011). A metabolomics approach revealed the mutualistic relationship between the diatom Thalassiosira pseudonana and the bacterium Dinoroseobacter shibae when vitamin $\mathrm{B}_{12}$ was not limiting. Dinoroseobacter shibae also had a significant effect on the growth of $T$. pseudonana at the early 
Table 1 Metabolic response of $P$. haitanensis

\begin{tabular}{|c|c|c|c|c|c|c|c|}
\hline Name & Class & $\mathrm{RI}^{\mathrm{a}}$ & $\mathrm{RT}^{\mathrm{b}}$ & $m / z^{\mathrm{c}}$ & $\begin{array}{l}p \text { value } \\
(\mathrm{B}-\mathrm{Ph} / \mathrm{Ph}-\mathrm{C})^{\mathrm{d}}\end{array}$ & $\log (\mathrm{B}-\mathrm{Ph} / \mathrm{Ph}-\mathrm{C})^{\mathrm{e}}$ & $\operatorname{VIP}^{\mathrm{f}}$ \\
\hline Octadecanoic acid & Fatty acid & 2247.2 & 14.8751 & 341.3 & 0.000421 & -0.4594 & 3.4544 \\
\hline Hexadecanoic acid & Fatty acid & 2049.7 & 13.9765 & 313.3 & 0.0013 & -0.4845 & 3.2618 \\
\hline Leucine & Amino acid & 1282.9 & 9.2537 & 158.1 & $3.52 \mathrm{E}-09$ & -0.7693 & 2.8377 \\
\hline Valine & Amino acid & 1227.0 & 8.7082 & 144.1 & $7.26 \mathrm{E}-08$ & -0.6022 & 2.1835 \\
\hline Serine & Amino acid & 1373.8 & 10.0187 & 218.1 & $1.97 \mathrm{E}-10$ & 0.8548 & 2.1463 \\
\hline Melibiose & Sugar & 3204.7 & 19.9937 & 204.1 & $1.31 \mathrm{E}-05$ & 0.4430 & 1.8439 \\
\hline Citric acid & Organic acid & 1840.9 & 12.9335 & 273.1 & 0.011481 & -0.5293 & 1.8325 \\
\hline Proline & Amino acid & 1307.8 & 9.4836 & 142.1 & $7.76 \mathrm{E}-09$ & -0.6711 & 1.8059 \\
\hline Glycerol-3-phosphate & Phosphate & 1782.6 & 12.6233 & 357.1 & $1.83 \mathrm{E}-06$ & 1.0526 & 1.5670 \\
\hline Tyrosine & Amino acid & 1960.4 & 13.5433 & 218.1 & $1.47 \mathrm{E}-06$ & -0.6932 & 1.2171 \\
\hline Threonine & Amino acid & 1400.3 & 10.2324 & 218.1 & 0.000274 & -0.1683 & 1.2001 \\
\hline Phenylalanine & Amino acid & 1646.0 & 11.8477 & 192.1 & $8.19 \mathrm{E}-09$ & -0.7601 & 1.1961 \\
\hline Isoleucine & Amino acid & 1304.0 & 9.4527 & 158.1 & $3.47 \mathrm{E}-05$ & -0.3881 & 1.1672 \\
\hline Galactosylglycerol & Glycols & 2352.7 & 15.3243 & 217.1 & $4.47 \mathrm{E}-08$ & 0.3757 & 1.1006 \\
\hline Alanine & Amino acid & 1112.4 & 7.3388 & 190.1 & 0.00078 & 0.2380 & 1.0985 \\
\hline
\end{tabular}

${ }^{\text {a }}$ Retention index

${ }^{\mathrm{b}}$ Retention time

${ }^{\mathrm{c}}$ Quantification mass

${ }^{\mathrm{d}}$ Student's $t$ test

${ }^{\text {e }}$ Logarithmic transformed fold change

${ }^{\mathrm{f}}$ VIP values obtained from PLS-DA

stage of the co-culture, influencing the metabolites of T. pseudonana including several amino acids, fatty acids, and C4 sugars (Paul et al. 2012).

Nutrient exchange behaviors also occur in terrestrial plant-bacterium symbioses, such as the reliance of Medicago truncatula (alfalfa) on the nitrogen-fixing bacterium Sinorhizobium meliloti. In this symbiotic system, the plant excretes flavonoid molecules that stimulate the bacteria to produce oligopolysaccharides known as the Nod factor (Gage 2004), which in turn induces plant root cell division and curling of the root hairs to incorporate a symbiotic bacterial colony, and is thus important for the initiation of the symbiosis (Jones et al. 2007).

It has been hypothesized that metabolite-mediated interactions are essential for ecosystem functioning (Paul et al. 2012). In this study, the bacteria Bacillus sp. WPySW2 promoted the relative growth rate of $P$. haitanensis at $20{ }^{\circ} \mathrm{C}$. Metabolites related to growth, energy storage, photosynthesis, and resistance-associated substances including organic acids, sugars, amines, glycols, and several amino acids of $P$. haitanensis were also altered when it was co-cultured with Bacillus sp. WPySW2, which could affect the physical status and environmental adaptation of the seaweeds in several ways (Yang et al. 2008).
Sugars The polysaccharides in $P$. haitanensis possess antioxidant and anti-aging activities (Zhang et al. 2003, 2010; Zhao et al. 2008) due to their free radical scavenging properties. Moreover, polysaccharides from Pyropia yezoensis have been found to have many physiological and nutraceutical activities, including antiviral, immunoregulatory, anticancer, anticoagulant, and antihyperlipidemic activities (Guo et al. 2007; Bhatia et al. 2013; Jiang 2014; Qian et al. 2014). Of the 72 identified metabolites, there were 4 polysaccharides (melibiose, cellotriose, maltose, and cellobiose) in the experimental group that exhibited changes in concentration (B-Ph; Fig. 3); however, only melibiose was found to be significantly upregulated $(p<0.05)$. Melibiose is an important disaccharide synthesized in the leaves during the photosynthesis of some plant species (Classen and Blaschek 1998) and is thought to be hydrolyzed from raffinose (Zhang et al. 2016).

The water-soluble polysaccharides produced by Ulva sp., such as rhamnose, xylose, glucose, mannose, and galactose, are used by epiphytic bacteria as a source of carbon and energy, resulting in the microbes gaining a competitive advantage in colonizing the host surface (Bruckner et al. 2011). The particulate acidic polysaccharides released by diatoms, such as transparent exopolymer particles (TEP), are abundant in the ocean and are often colonized by bacteria (Passow 2002). These acidic polysaccharides are used by active diatoms to 
Fig. 4 Metabolite-metabolite correlations of samples. a Control samples (Ph-C). b Co-culture samples (B-Ph)
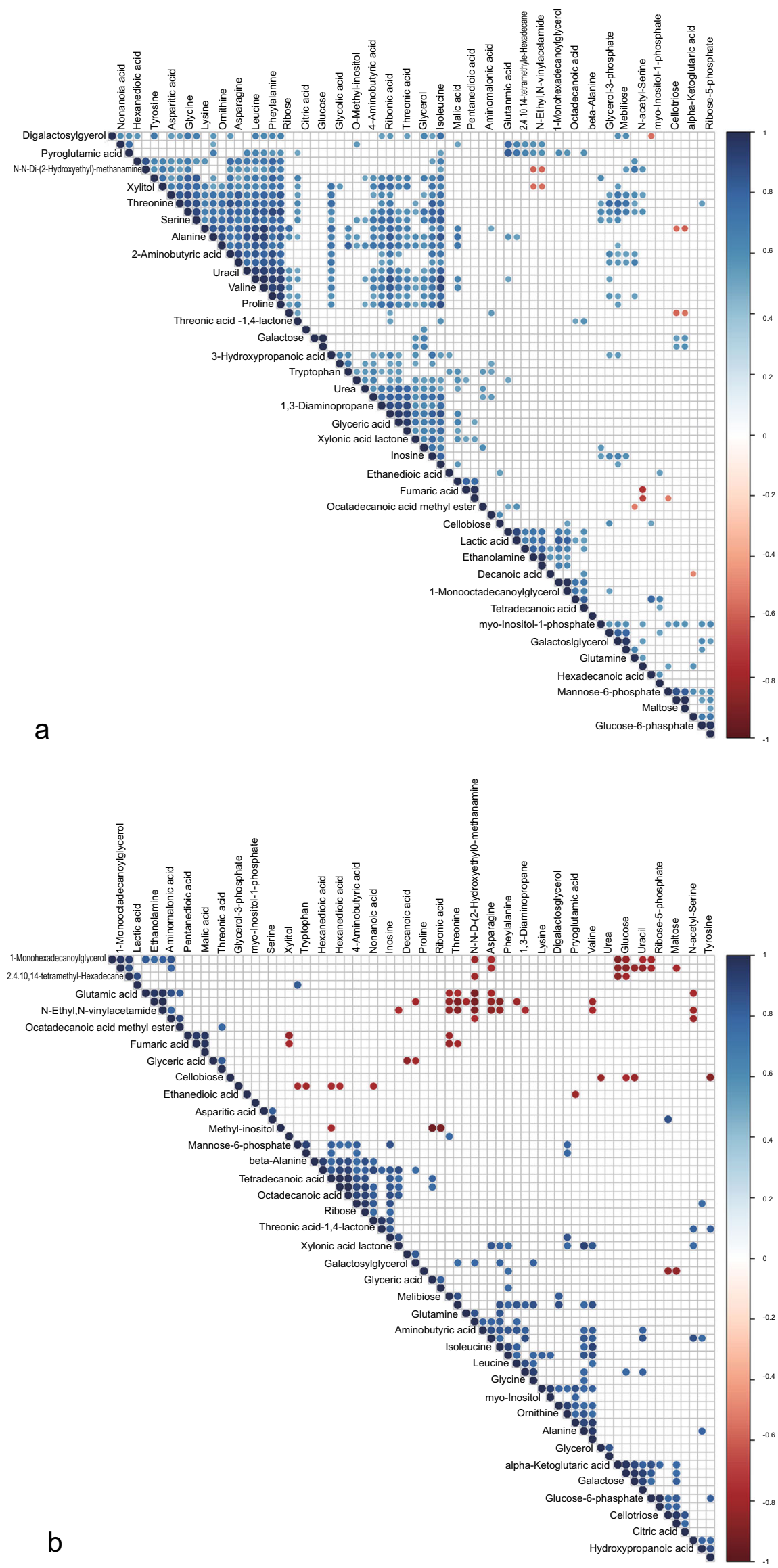


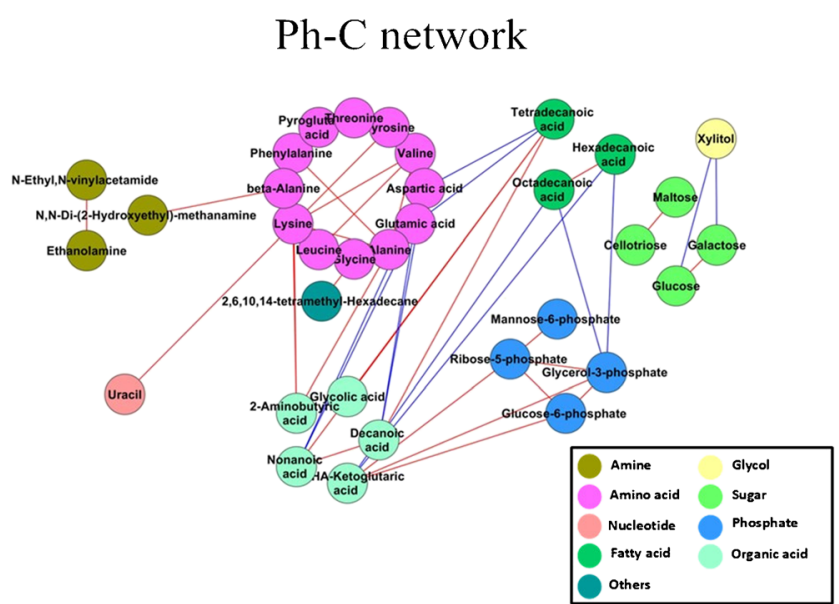

Fig. 5 Correlation-based network analysis to identify P. haitanensis

recruit specific bacteria. The bacteria recognize the diatom and initiate attachment to the surface of the host, which provides the polysaccharides for the bacteria as a nutrient source.

Sugars and their derivatives have also been found to act as inducers for invertebrate settlement on the surface of seaweeds (Steinberg et al. 2001). These polysaccharides were also found in the metabolites of $P$. haitanensis and might provide the nutrients for the bacteria, which was substantiated by the fact that the bacteria could not survive in seawater but could grow well when they were co-cultured with the alga without additional nutrients (unpublished data).

Glycols Galactosylglycerol is a natural glycoside which is an important structural unit of glycoglycerolipid (Wei et al. 2013). The metabolite $\alpha$-galactosylglycerol is a kind of isofloridoside and has an important role in regulating the osmotic balance to maintain physiological stasis in the golden brown alga Ochromonas malhamensis (Kauss 1973). Its structure is similar to isoflorid-oside/floridoside which has three isomeric forms, floridoside ( $\alpha$-D-galactopyranosyl-(-1 $\rightarrow 2$ )D-glycer-ol), D-isofloridoside ( $\alpha$-D-galactopyranosyl-(-1 $\rightarrow$ $1)$-D-glycerol), and L-isofloridoside ( $\alpha$-D-galactopyranosyl-( $(\rightarrow 1)$-L-glycerol) in the red alga $P$. haitanensis (Karsten et al. 1993). It is synthesized by $\beta$-galactosidase catalyzed reverse hydrolysis of galactose and glycerol (Wei et al. 2013).

On account of storage time being short in the cytosol, glycols are broken down into other carbohydrates such as red algal starch and the precursors of agar (Song 2014). In many single-cell red algae, galactosylglycerols are directly synthesized to the carbon precursors of cell wall polysaccharides ( $\mathrm{Li}$ et al. 2002). In addition, this might be crucial for carbon transfer between some species of the cyanobacterial genus Microcystis and their hosts (Simon-Colin et al. 2004).

The red alga $P$. haitanensis in the intertidal zone is periodically exposed to air where it undergoes a variety of potentially stressful environmental changes, including abiotic stress (salinity, temperature, and seasonal factors) and biological stress by phycosphere microorganisms (Karsten and West 2000; Reed 1985; Reed et al. 1980). Compared with the control $(\mathrm{Ph}-\mathrm{C})$, the co-cultured $P$. haitanensis $(\mathrm{B}-\mathrm{Ph})$ contained significantly more galactosylglycerol in our study. It is suggested that the accumulation of galactosylglycerol in $P$. haitanensis could help maintain osmotic balance and facilitate adaptation to the environment when co-cultured with the phycosphere bacteria Bacillus sp.

Phosphate Glycerol-3-phosphate (G3P), an intermediate product of the fatty acid metabolism pathway, is involved in energy-producing reactions including glycolysis and glycerolipid biosynthesis and acts as a regulator of plant defense signaling. In this study, the concentration of G3P increased significantly in the co-cultured $P$. haitanensis (Fig. 3). G3P could be processed into floridosides, an important osmoprotectant in intertidal red algae, functioning in abiotic stress resistance reactions in Pyropia (Ye et al. 2013; Qian et al. 2015). However, glycoside metabolites were not detected by GC-MS in this study.

G3P, derived from glycerol in terrestrial plants, plays an important role in providing basal defense in the interaction of plant roots with fungal symbionts (Chanda et al. 2008). It was found that the glycerol content reduced while concomitantly increasing the G3P content in Arabidopsis infected by Colletotrichum higginsianum (Srivathsa et al. 2009). Strikingly, the accumulation of G3P in the plant tissues during interactions with microbes preceded the accumulation of other metabolites known to be essential for resistance responses (Chanda et al. 2011).

Amino acids Some amino acids are thought to be involved in stress resistance reactions in many algae. Proline is an essential constituent of most proteins and participates in many metabolic activities and is important in maintaining the osmotic balance of algal cells (Saha et al. 2014). Leucine, isoleucine, and valine are involved in deamination and transamination reactions connected with the tricarboxylic (TCA) cycle (Kakinuma et al. 2006). Ye et al. (2013) reported that the amounts of these amino acids increased in the hightemperature tolerant strains of $P$. haitanensis.

In this study, the concentrations of proline, tyrosine, threonine, leucine, isoleucine, valine, and phenylanin were strongly downregulated in $P$. haitanensis co-cultured with the bacteria (Fig. 3 and Table 1). Saha et al. (2012) reported that proline concentrations of $0.01 \mathrm{ng} \mathrm{cm}^{-2}$ or more were sufficient for a partial inhibition of all but the most resistant strains of Cytophaga sp. on the surface of Fucus vesiculosus.

The concentrations of alanine and serine were upregulated in the co-cultured P. haitanensis samples in this study. Alanine accumulation is a common response in plants and animals to a variety of stress conditions, such as anoxia and extreme 
temperatures (Eberlee and Storey 1988; Nissim et al. 1992). It has been proposed that alanine is a universal primary stress signal expressed by cells (Monselise et al. 2003). Compared with those at suitable temperatures, heat-stressed $P$. haitanensis were found to contain significantly more alanine, which is thought to act as an osmoprotectant in hightemperature tolerance reactions (Ye et al. 2013).

It has also been reported that alanine acts as a trigger to promote the probiotics of rice (Oryza sativa) to protect the plant against biofilms (Jones et al. 2011). However, serine is a precursor of G3P, which contributes to bacterial niche specificity through gene selection. This host metabolite has been found to further refine the response of bacteria to their environment and can dramatically affect the outcome of the hostpathogen interaction (Connolly et al. 2015). In addition, the human body contains serine at various extraintestinal sites, which ensures appropriate bacterial colonization (Connolly et al. 2016). Whether the accumulation of alanine and serine in $P$. haitanensis possesses a similar function of ensuring appropriate bacterial colonization requires further study.

The changes in the stress-related amino acids might indicate a reciprocal relationship between $P$. haitanensis and Bacillus sp. WPySW2 being constructed under such coculture conditions. It was also previously demonstrated that free amino acids could enhance the primary production of seaweeds (Flynn and Wright 1986; Linares 2006), which might explain the promoted algal growth and bacterial colonization in co-culture.

Fatty acids Octadecanoic acid and hexadecanoic acid were significantly reduced in P. haitanensis when the phycosphere epibiotic bacteria were added (Fig. 3). Increasing evidence shows both $\mathrm{C} 18$ and $\mathrm{C} 16$ fatty acids and their derivatives act as signaling molecules, modulating normal and diseaserelated physiologies in some organisms (Kachroo and Kachroo 2009). Fatty acids (FAs) secreted by many algae act as antibacterial compounds to protect against unwanted and/or algicidal bacteria. The diatom Navicula delognei was found to produce hexadecatetraenoic acid and octadecatetraenoic acid, derived from octadecanoic and hexadecanoic acid, which displayed strong antibacterial activity against the pathogens Staphylococcus aureus, Staphylococcus epidermidis, Proteus vulgaris, and Salmonella enterica (Amin et al. 2012).

Organic acids Current knowledge shows that citric acid not only acts as an intermediate in carbon metabolism, but also as a key component in mechanisms that some plants use to cope with nutrient deficiencies, metal tolerance, and the operation of plant-microbe interactions (López-Bucio et al. 2000). Citric acid is an organic acid that has been proposed to be involved in those processes and is involved in energy production as photosynthetic intermediates in the TCA cycle
(Jones 1998). There is some evidence that organic acid excretion could play an important role in phosphate solubilization and was first discovered when researchers found that the roots of certain plant species grown under phosphorusdeficient conditions contain higher concentrations of organic acids than non-stressed plants (Struthers and Sieling 1950; Bradley and Sieling 1953). It is well known that nitrogen and phosphorus are essential for plant growth, development and reproduction (López-Bucio et al. 2000). In this study, the concentration of citric acid decreased significantly in the co-cultured $P$. haitanensis samples (B-Ph; $p<0.05$, Fig. 3), while the control $(\mathrm{Ph}-\mathrm{C})$ increased significantly. The result might indicate that the accumulation of citric acid enhanced resistance to stress, while co-culture could reduce environmental stress.

On one hand, the epiphytic bacteria Bacillus sp. WPySW2 changed the metabolite composition of seaweeds and promoted the growth of $P$. haitanensis in co-culture; on the other hand, it is envisaged that some metabolites produced by the phycosphere microbes act as a growth regulator. Some studies suggest that the genus Bacillus can promote plant growth directly through nitrogen fixation, phosphate solubility, and the production of phytohormones and 1-aminocyclopropane-1carboxylic acid (ACC) deaminase and indirectly by the production of antagonistic compounds such as hydrolytic enzymes, siderophores, bacterial volatile compounds (BVCs), and a range of antibiotics (Parke and Doug 2001; Govindasamy et al. 2010; Zulma et al. 2012; da Costa et al. 2014; Chung et al. 2015; Bach et al. 2016). Thus, it is necessary to study microbial metabolism to comprehensively assess the symbiotic relationship between seaweeds and bacteria in particular.

In summary, the results demonstrated that $P$. haitanensis grew better when it was co-cultured with Bacillus sp. WPySW2 at $20{ }^{\circ} \mathrm{C}$. Several main intracellular metabolites were downregulated or upregulated, which might facilitate bacterial colonization. Thus, a mutually beneficial relationship between P. haitanensis and epibiotic bacteria was identified as a contributor towards the maintenance of a stable phycosphere biological system. The combination of GC-MS-based metabolic profiling with multivariate analysis could potentially be a useful tool for discriminating the relationship between $P$. haitanensis and Bacillus sp. WPySW2 and determining the potential indicators of healthy algae-bacteria coexistence in ecosystems.

Acknowledgements This research was financially supported by the National Nature Science Foundation of China (\#31772871), China Spark Program (\#2015GA701001), and the Open Fund of Zhejiang Provincial Top Key Discipline of Aquaculture in Ningbo University (\#xkzsc1509), Li Dak Sum Yip Yio Chin Kenneth Li Marine Biopharmaceutical Development Fund, National 111 Project of China, Liu Kong Aiju Education Fund in Ningbo University, and K. C. WONG Magna Fund in Ningbo University. 


\section{Compliance with ethical standards}

Conflict of interest The authors declare that they have no conflict of interest.

Open Access This article is distributed under the terms of the Creative Commons Attribution 4.0 International License (http:// creativecommons.org/licenses/by/4.0/), which permits unrestricted use, distribution, and reproduction in any medium, provided you give appropriate credit to the original author(s) and the source, provide a link to the Creative Commons license, and indicate if changes were made.

\section{References}

Agarrwal R, Bentur JS, Nair S (2014) Gas chromatography mass spectrometry based metabolic profiling reveals biomarkers involved in rice-gall midge interactions. J Integr Plant Biol 56:837-848

Albakosh MA, Naidoo RK, Kirby B, Bauer R (2016) Identification of epiphytic bacterial communities associated with the brown alga Splachnidium rugosum. J Appl Phycol 28:1891-1901

Amin S, Parker M, Armbrust E (2012) Interactions between diatoms and bacteria. Microbiol Mol Biol Rev 6:667-684

Bach E, dos Santos Seger GD, de Carvalho Fernandes G, Lisboa BB, Passaglia LMP (2016) Evaluation of biological control and rhizosphere competence of plant growth promoting bacteria. Appl Soil Ecol 99:141-149

Bell W, Mitchell R (1972) Chemotactic and growth responses of marine bacteria to algal extracellular products. Biol Bull 143:265-277

Benjamini Y, Yekutieli D (2001) The control of the false discovery rate in multiple testing under dependency. Ann Stat 29:1165-1188

Bhatia S, Rathee P, Sharma K, Chaugule BB, Kar N, Bera T (2013) Immunomodulation effect of sulphated polysaccharide (porphyran) from Porphyra vietnamensis. Int J Biol Macromol 57:50-56

Bradley D, Sieling D (1953) Effect of organic anions and sugars on phosphate precipitation by iron and aluminum as influenced by pH. Soil Sci 76:175-179

Bruckner CG, Rehm C, Grossart H-P, Kroth PG (2011) Growth and release of extracellular organic compounds by benthic diatoms depend on interactions with bacteria. Environ Microbiol 13:10521063

Cai X, Lin C, He H, Hu F (2005) Effects of endophytic bacterial strain BS-2 on rice seeding growth. J Fujian Agr Forestry Univ (Natural Science Edition) 34:189-194

Cao Y, He S, Zhou Z, Zhang M, Wei M, Zhang H, Yao B (2012) Orally administere thermostable $\mathrm{N}$-acyl homoserine lactonase from Bacillus sp. strain AI96 attenuates Aeromonas hydrophila infection in zebrafish. Appl Env Microbiol 78:1899-1908

Carvalho AP, Batista D, Dobretsov S, Coutinho R (2017) Extracts of seaweeds as potential inhibitors of quorum sensing and bacterial growth. J Appl Phycol 29:789-797

Chanda B, Venugopal SC, Kulshrestha S, Navarre DA, Downie B, Vaillancourt L, Kachroo A, Kachroo P (2008) Glycerol-3phosphate levels are associated with basal resistance to the hemibiotrophic fungus Colletotrichum higginsianum in Arabidopsis. Plant Physiol 147:2017-2029

Chanda B, Xia Y, Mandal MK, Yu K, Sekine KT, Gao QM, Selote D, Hu Y, Stromberg A, Navarre D, Kachroo A, Kachroo P (2011) Glycerol-3-phosphate is a critical mobile inducer of systemic immunity in plants. Nat Genet 43:421-427

Chen MX, Xu JY, Pan QW, Gao XY (2011) Analysis of nutritional composition and polysaccharide composition in low-value Porphyra haitanensis. Food Sci 32:230-234
Chevanton ML, Garnier M, Bougaran G, Schreiber N, Lukomska E, Bérard JB, Fouilland E, Bernard O, Cadoret JP (2013) Screening and selection of growth-promoting bacteria for Dunaliella cultures. Algal Res 2:212-222

Chung J, Song GC, Ryu CM (2015) Sweet scents from good bacteria: case studies on bacterial volatile compounds for plant growth and immunity. Plant Mol Biol 90:1-11

Classen B, Blaschek W (1998) High molecular weight acidic polysaccharides from Malva sylvestris and Alcea rosea. Planta Med 64:640 644

Connolly JPR, Goldstone RJ, Burgess K, Cogdell RJ, Beatson SA, Vollmer W, Smith DGE, Roe AJ (2015) The host metabolite Dserine contributes to bacterial niche specificity through gene selection. ISME J 9:1039-1051

Connolly JPR, Gabrielsen M, Goldstone RJ, Grinter R, Wang D, Cogdell RJ, Walker D, Smith DGE, Roe AJ (2016) A highly conserved bacterial D-serine uptake system links host metabolism and virulence. PLoS Pathog 12:e1005359

Cooper MB, Smith AG (2015) Exploring mutualistic interactions between microalgae and bacteria in the omics age. Curr Opin Plant Biol 26:147-153

Costa PBd, Granada CE, Ambrosini A, Moreira F, Souza Rd, dos Passos JFM, Arruda L, P. Passaglia LMP (2014) A model to explain plant growth promotion traits: a multivariate analysis of 2211 bacterial isolates. PLOs One 9:e116020-e116020

Dawud RA, Schreiber K, Schomburg D, Adjaye J (2012) Human embryonic stem cells and embryonal carcinoma cells have overlapping and distinct metabolic signatures. PLoS One 7:1634-1634

Eberlee J, Storey K (1988) Tissue-specific biochemical responses during anoxia and recovery in the channeled whelk. J Exp Mar Biol Ecol 121:165-176

Egan S, Darder T, Burke C, Sternber P, Kjelleberg S, Thomas T (2013) The seaweed holobiont: understanding seaweed-bacteria interactions. FEMS Microbiol Rev 37:462-476

Fang WY, Yang R, Zhu P, Shan YY, Yan XJ (2009) Antibacterial activity of Porphyra spp. epiphytic bacteria and polyketide synthase I gene screening. Acta Microbiol Sinica 49:153-160

Farag MA, Porzel A, Wessjohann LA (2012) Comparative metabolite profiling and fingerprinting of medicinal licorice roots using a multiplex approach of GC-MS, LC-MS and ID NMR techniques. Phytochemistry 76:60-72

Fernandes N, Steinberg P, Rusch D, Kjelleberg S, Thomas T (2012) Community structure and functional gene profile of bacteria on healthy and diseased thalli of the red seaweed Delisea pulchra. PLoS One 7:e50854

Flynn KJ, Wright CRN (1986) The simultaneous assimilation of ammonium and L-arginine by the marine diatom Phaeodactylum tricornutum Bohlin. J Exp Mar Biol Ecol 95:257-269

Gage DJ (2004) Infection and invasion of roots by symbiotic, nitrogen fixing rhizobia during nodulation of temperate legumes. Microbiol Mol Biol Rev 68:280-300

Govindasamy V, Senthilkumar M, Magheshwaran V, Kumar U, Bose P Sharma V, Annapurna K (2010) Bacillus and Paenibacillus spp.: potential PGPR for sustainable agriculture. In: Maheshwari DK (ed) Plant growth and health promoting bacteria. Springer, Berlin, pp 333-364

Guo TT, Xu HL, Zhang LX, Zhang JP, Guo YF, Gu JW, He PM (2007) In vivo protective effect of Porphyra yezoensis polysaccharide against carbon tetrachloride induced hepatotoxicity in mice. Regul Toxicol Pharmacol 49:101-106

Hawksworth DL (1988) The variety of fungal-algal symbioses, their evolutionary significance, and the nature of lichens. Bot J Linn Soc 96:3-20

Helliwell KE, Wheeler GL, Leptos KC, Goldstein RE, Smith AG (2011) Insights into the evolution of vitamin $\mathrm{B}_{12}$ auxotrophy from sequenced algal genomes. Mol Biol Evol 28:2921-2933 
Hodson S, Deery E, Warren M, Croft M, Smith A (2005) Algae acquire vitamin $\mathrm{B}_{12}$ through a symbiotic relationship with bacteria. Nature 438:90-93

Huang B, Yan X (2010) Study on the red rotting disease of Porphyra blades. J Shanghai Ocean Univ 19:226-231

Jiang LF (2014) The polysaccharides from Porphyra yezoensis suppress the denaturation of bighead carp myofibrillar protein. Int J Biol Macromol 68:18-20

Jones D (1998) Organic acids in the rhizosphere - a critical review. Plant Soil 205:25-44

Jones KM, Kobayashi H, Davies BW, Taga ME, Walker GC (2007) How rhizobial symbionts invade plants: the Sinorhizobium-Medicago model. Nat Rev Microbiol 5:619-633

Jones OAH, Maguire ML, Griffin JL, Jung YH, Shibato J, Rakwal R, Agrawal GK, Jwa NS (2011) Using metabolic profiling to assess plant-pathogen interactions: an example using rice (Oryza sativa) and the blast pathogen Magnaporthe grisea. Eur J Plant Pathol 129:539-554

Kachroo A, Kachroo P (2009) Fatty acid-derived signals in plant defense. Annu Rev Phytopathol 47:153-176

Kain JM (1987) Seasonal growth and photoinhibition in Plocamium cartilagineum (Rhodophyta) off the Isle of Man. Phycologia 26: 88-99

Kakinuma M, Coury DA, Kuno Y, Itoh S, Kozawa Y, Inagaki E, Yoshiune Y, Amano H (2006) Physiological and biochemical responses to thermal and salinity stresses in a sterile mutant of Ulva pertusa (Ulvales, Chlorophyta). Mar Biol 149:97-106

Karsten U, West JA (2000) Living in the intertidal zone-seasonal effects on heterosides and sun-screen compounds in the red alga Bangia atropurpurea (Bangiales). J Exp Mar Biol Ecol 254:221-234

Karsten U, Barrow KD, King RJ (1993) Floridoside, L-isofloridoside, and D-isofloridoside in the red alga Porphyra columbina (seasonal and osmotic effects). Plant Physiol 103:485-491

Kauss H (1973) Turnover of galactosyiglycerol and osmotic balance in Ochromonas. Plant Physiol 52:613-615

Kouzuma A, Watanabe K (2015) Exploring the potential of algae/bacteria interactions. Curr Opin Biotechnol 33:125-129

Lachnit T, Wahl M, Harder T (2010) Isolated thallus-associated compounds from the macroalga Fucus vesiculosus mediate bacterial surface colonization in the field similar to that on the natural alga. Biofouling 26:247-255

Lane AL, Nyadong L, Galhena AS, Shearer TL, Stout EP, Parry RM, Wasnika MK, Wangc MD, Hayb ME, Fernandeza FM, Kubaneka J (2009) Desorption electrospray ionization mass spectrometry reveals surface-mediated antifungal chemical defense of a tropical seaweed. Proc Natl Acad Sci U S A 106:7314-7319

Li SY, Shabtai Y, Arad S (2002) Floridoside as a carbon precursor for the synthesis of cell-wall polysaccharide in the red microalga Porphyridium sp. (Rhodophyta). J Phycol 38:931-938

Linares F (2006) Effect of dissolved free amino acids (DFAA) on the biomass and production of microphytobenthic communities. J Exp Mar Biol Ecol 330:469-481

Lion U, Wiesemeier T, Weinberger F, Beltran J, Flores V, Faugeron S, Corrrea J, Pohnert G (2006) Phospholipases and galactolipases trigger oxylipin-mediated wound activated defence in the red alga Gracilaria chilensis against epiphytes. Chem Biol Chem 7:457-462

Lisec J, Schauer N, Kopka J, Willmitzer L, Fernie AR (2006) Gas chromatography mass spectrometrybased metabolite profiling in plants. Nat Protoc 1:387-396

López-Bucio J, Nieto-Jacobo M, Ramírez-Rodríguez V, Herrera-Estrella L (2000) Organic acid metabolism in plants: from adaptive physiology to transgenic varieties for cultivation in extreme soils. Plant Sci 160:1-13

Monselise B, Parola A, Kose D (2003) Low-frequency electromagnetic fields induce a stress effect upon higher plants, as evident by the universal stress signal, alanine. Biochem Biophys Res Commun 302:427-434

Nissim I, Hardy M, Pleasure J, Nisim I, States B (1992) A mechanism of glycine and alanine cytoprotective action; stimulation of stress-induced HSP70 mRNA. Kidney Int 42:775-782

Nylund GM, Persson F, Lindegarth M, Cervin G, Hermansson M, Pavia $\mathrm{H}$ (2010) The red alga Bonnemaisonia asparagoides regulates epiphytic bacterial abundance and community composition by chemical defence. FEMS Microbiol Ecol 71:84-93

Olmos-Soto J (2014) Bacillus subtilis a potential probiotic bacterium to formulate functional feeds for aquaculture. J Microb Biochem Technol 6:361-365

Parke J, Doug G (2001) Diversity of the Burkholderia cepacia complex and implications for risk assessment of biological control strains. Annu Rev Phytopathol 39:225-258

Passow U (2002) Production of transparent exopolymer particles (TEP) by phyto- and bacterioplankton. Mar Ecol Prog Ser 236:1-12

Patrick FM (1978) The use of membrane filtration and Marine Agar $2216 \mathrm{E}$ to enumerate marine heterotrophic bacteria. Aquaculture 13:369-372

Paul C, Mausz MA, Pohnert G (2012) A co-culturing/metabolomics approach to investigate chemically mediated interactions of planktonic organisms reveals influence of bacteria on diatom metabolism. Metabolomics 9:349-359

Persson F, Svensson R, Nylund GM, Fredriksson NJ, Pavia H, Hermansson M (2011) Ecological role of a seaweed secondary metabolite for a colonizing bacterial community. Biofouling 27:579588

Qian L, Zhou Y, Ma J (2014) Hypolipidemic effect of the polysaccharides from Porphyra yezoensis. Int J Biol Macromol 68:48-49

Qian FJ, Luo QJ, Yang R, Zhu ZJ, Chen HM, Yan XJ (2015) The littoral red alga Pyropia haitanensis uses rapid accumulation of floridoside as the desiccation acclimation strategy. J Appl Phycol 27:621-632

Real BD, Ortiz MC, Sarabia LA (2012) Develop of a multiway chemometric-based analytical method fulfilling regulatory identification criteria: application to GC-MS pesticide residue analysis. J Chromatogr B 910:122-137

Reed R (1985) Osmoacclimation in Bangia atropurpurea (Rhodophyta, Bangiales): the osmotic role of floridoside. Br Phycol J 20:211-218

Reed R, Collins J, Russell G (1980) The effects of salinity upon galactosyl-glycerol content and concentration of the marine red alga Porphyra purpurea (Roth) C.Ag. J Exp Bot 31:1539-1554

Saha M, Rempt M, Gebser B, Grueneberg J, Pohnert G, Weinberger F (2012) Dimethylsulphopropionate (DMSP) and proline from the surface of the brown alga Fucus vesiculosus inhibit bacterial attachment. Biofouling 28:593-604

Saha M, Rempt M, Stratil SB, Wahl M, Pohnert G, Weinberger F (2014) Defence chemistry modulation by light and temperature shifts and the resulting effects on associated epibacteria of Fucus vesiculosus. PLoS One 9:e105333

Sangster T, Major H, Plumb R, Wilson AJ, Wilson ID (2006) A pragmatic and readily implemented quality control strategy for HPLC-MS and GC-MS-based metabonomic analysis. Analyst 131:1075-1078

Seyedsayamdost MR, Case RJ, Kolter R, Clardy J (2011) The Jekyll-andHyde chemistry of Phaeobacter gallaeciensis. Nat Chem 3:331-335

Shen ML, Yang R, Luo QJ, Wang SG, Ren JR (2013) Microbial diversity of Pyropia haitanensis phycosphere during cultivation. Acta Microbiol Sin 53:1087-1102

Simon-Colin C, Kervarec N, Pichon R, Deslands E (2004) NMR ${ }^{13}$ Cisotopic enrichment experiments to study carbon partitioning into organic solutes in the red alga Grateloupia doryphora. Plant Physiol Biochem 42:21-26

Song DD (2014) The changes of floridoside content and the expression of stress resistance related genes in Pyropia haitanensis (Rhodophyta) under heat stress. Dissertation, University of Ningbo, China 
Song DD, Yang R, Ren JR, Mo YT, Wen X (2014) Effects of environmental $\mathrm{pH}$ and Psuedoalteromonas sp. NPyS3 on the Pleurochrysis carterae. J Biol 31:50-54

Srivathsa C, Chanda V, Vaillancourt L, Kachroo A, Kachroo P (2009) The common metabolite glycerol-3-phosphate is a novel regulator of plant defense signaling. Plant Signal Behav 4:746-479

Steinberg PD, de Nys R, Kjelleberg S (2001) Chemical mediation of surface colonization. In: McClintock JB, Baker BJ (eds) Marine chemical ecology. CRC Press, Boca Raton, pp 354-387

Struthers P, Sieling D (1950) Effect of organic anions on phosphate precipitation by iron and aluminum as influenced by $\mathrm{pH}$. Soil Sci 69 : 205-214

Takahashi M, Ichitani T, Sasaki M (1977) Pythium porphyrae Takahashi et Sasaki, sp. nov. causing red rot of marine red algae Porphyra spp. Trans Mycol Soc Jpn 18:279-285

Uarrota VG, Moresco R, Coelho B, Nunes EC, Peruch LAM, Neubert EO, Rocha M, Maraschin M (2014) Metabolomics combined with chemometric tools (PCA, HCA, PLS-DA and SVM) for screening cassava (Manihot esculenta Crantz) roots during postharvest physiological deterioration. Food Chem 161:67-78

Vairappan CS, Suzuki M, Ishii T, Okino T, Abe T, Masuda M (2008) Antibacterial activity of halogenated sesquiterpenes from Malaysian Laurencia spp. Phytochemistry 69:2490-2494

Vijayalakshmi S (2015) Screening for antibacterial activity of marine bacteria from seaweeds. STAR J 4:185-189

Vlamakis H, Chai Y, Beauregard P, Losick R, Kolter R (2013) Sticking together: building a biofilm the Bacillus subtilis way. Nat Rev Microbiol 11:157-168

Wahl M, Goecke F, Labes A, Dobretsov S, Weinberger F (2012) The second skin: ecological role of epibiotic biofilms on marine organisms. Front Microbiol 3:292

Wang H, Li X, Xia Y, Yan B (2011) Isolation, identification and biological pathogen of yellow spot disease in conchocelis of Porphyra yezoensis. Mar Environ Sci 30:361-364

Wei W, Qi D, Zhao H, Lu Z, Lv F, Bie X (2013) Synthesis and characterisation of galactosyl glycerol by $\beta$-galactosidase catalysed reverse hydrolysis of galactose and glycerol. Food Chem 141:3085-3092

Weinberger F, Lion U, Delage L, Kloareg B, Potin P, Beltrá J, Flores V, Faugeron S, Correa J, Pohnert G (2011) Up-regulation of lipoxygenase, phospholipase, and oxylipin-production in the induced chemical defense of the red alga Gracilaria chilensis against epiphytes. J Chem Ecol 37:677-686
Yan Y, Ma J, Xu P, Sun Q, Wang H (2002) Pseudoalteromonas citrea, the causative agent of green-spot disease of Porphyra yezoensis. J Fish Sci China 9:353-358

Yan X, Huang B, Zhou X, Li L (2008) Study on a bacterial red-rotting disease of Porphyra haitanensis (Bangiales, Rhodophyta). J Fish Sci China 15:313-319

Yang R, Fang WY, Shan YY, Chen HM, Sun X, Ye YF (2008) Genetic diversity of epiphytic bacteria in Porphyra yezoensis. Acta Oceanol Sinica 30:161-168

Yang XJ, Chen FR, Gan L, Du YX, Ruan HC (2010) Effect of the endophytic Bacillus subtilis EBT1 isolated from banana on the growth and resistance to Fusarium wilt disease in banana. Acta Phytophylacica Sinica 37:299-306

Ye YF, Zhang LM, Yang R, Luo QJ, Chen HM, Yan XJ, Tang HR (2013) Metabolic phenotypes associated with high-temperature tolerance of Porphyra haitanensis strains. J Agric Food Chem 61:8356-8363

Zhang Q, Li N, Zhou G, Lu X, Xu Z, Li Z (2003) In vivo antioxidant activity of polysaccharide fraction from Porphyra haitanensis (Rhodophyta) in aging mice. Pharmacol Res 48:151-155

Zhang ZX, Liu P, Kang HJ, Liao CC, Chen ZL, Xu GD (2008) A study of the diversity of different geographical populations of Emmenopterys henryi using FTIR based on principal component analysis and cluster analysis. Spectrosc Spectr Anal 28:2081-2086

Zhang Z, Zhang Q, Wang J, Song H, Zhang H, Niu X (2010) Regioselective syntheses of sulfated porphyrans from Porphyra haitanensis and their antioxidant and anticoagulant activities in vitro. Carbohydr Polym 79:1124-1129

Zhang WT, Yue C, Huang QW, Yuan K, Yan AJ, Shi S (2016) Contents of eight saccharides in unprocessed and processed Rehmannia glutinosa and content changes at different processing time points. Chin Tradit Herb Drug 47:1132-1136

Zhao T, Zhang Q, Qi H, Liu X, Li Z (2008) Extension of life span and improvement of vitality of Drosophila melanogaster by long-term supplementation with different molecular weight polysaccharides from Porphyra haitanensis. Pharmacol Res 57:67-72

Zhou JM, Yang R, Fang WY, Shen ML, Sun X, Wu XK (2012) Study on the axenic culture and application of Porphyra haitanensis thallus. J Biol 29:83-87

Zulma R, Jesús C, Bruna G, Lucia M, James E, Venturi V (2012) Common features of environmental and potentially beneficial plant-associated Burkholderia. Microb Ecol 63:249-266 